\title{
Design and performance evaluation of a horizontal hydraulic honing attachment to lathe
}

\author{
K. Kishore' ${ }^{1}$, P.V. Gopal Krishna ${ }^{2}$, G. Kiran Kumar ${ }^{3}$, T. Srihari ${ }^{4}$ \\ ${ }^{1,2,3}$ Department of Mechanical Engineering, Vasavi College of Engineering, Hyderabad, INDIA \\ ${ }^{4}$ Shadan College of Engineering and Technology, Hyderabad, INDIA \\ *Corresponding Author: email: gopal_pola@yahoo.co.uk
}

\begin{abstract}
The surface finish between two mating parts in an assembly has significant influence on the mechanical properties such as wear resistance, corrosion resistance, fatigue resistance and stress concentration. The choice of surface finishing operation such as honing and lapping is based on functional requirements of an assembly. As these processes are expensive, the design engineer should be cautious in assigning the quantified surface roughness value. Traditionally, honing is carried out in vertical direction. The process is capable of correcting the inner surface geometry while maintaining a surface finish band between 0.25 to 1 micron $(\mu \mathrm{m})$. Cylinder liners, hydraulic cylinders, and gears are routinely finished by honing process. An attempt is made in the present work by retrofitting an existing lathe. A geared $\mathrm{AC}$ motor is mounted at the end of the lathe bed, and a fixture for holding a liner is mounted at the other end. The honing tool gets its primary motion from the geared motor and a hydraulic circuit is used for feed motion. Experiments are carried to evaluate the surface finish against the process parameters such as grain size, feed rate and speed. The results obtained are superior to internal grinding and are comparable to original honing. Surface roughness is measured for coarse, medium and fine grain honing shoes. Optimum feed rate, grain size are extracted from experiments. The work material considered for present investigations is a diesel engine cylinder liner.
\end{abstract}

Keywords: Honing, Surface roughness, Talysurf, Grain size, Feed, Wheel speed, Cylinder liner

DOI: http://dx.doi.org/10.4314/ijest.v6i1.12

\section{Introduction}

Honing is a finishing process, in which a tool called hone carries out a combined rotary and reciprocating motion while the work piece is stationary. Average roughness up to $0.1 \mu \mathrm{m}$ can be attained. Most honing is done on internal cylindrical surface, such as automobile cylindrical walls. The honing stones are held against the work piece with controlled light pressure. The honing head is not guided externally but, instead, floats in the hole, being guided by the work surface. It is desired that honing stones should not leave the work surface. Stroke length must cover the entire work length. Finishing of cylinders for internal combustion engines, air bearing spindles, gears and hydraulic cylinders are finished by honing. The advantages of the honing are: re-texturing the ground edge, removal of burr, second bevel and high quality surface finish. Geometry corrections are difficult while honing outer surface of cylinders. The cost and time of machining is high. The critical process parameters are: rotation speed, length and position of the stroke, honing stick pressure, grain size of honing sticks.

Honing wheel structure is optimized to improve machining accuracy and reduce the honing wheel wear in plane honing by .Guo (2002) The important characteristics in honing cast iron cylinder blocks and the influence in the internal combustion engine performance was described and discussed by Anderberg, (2013). The design optimization of segmented grinding wheel structure on high speed was reported by Zhang (2010). The influence of scratches left in honing process on the economy and longevity of IC Engines was carried out by Dimkovski [2009], along with his co investigators in Volvo group, has examined and conducted experiments on different worn engine liners, to develop an algorithm, that can identify the smeared metal at different zones along the liner. Vornov (2009) developed a model for deep hole honing process. The dynamic model of honing, that includes the models 
of tool dynamics, cutting forces calculation, and new surface formation, are presented. Investigations in plate honing are carried out by Rodrigues (2005) the paper reports the optimization of the structure parameters by computing the machining accuracy coefficient and wear coefficient of honing wheels. Kanthababu (2008) used Acoustic Emission (AE) signals from the machining process and found that it is one of the most promising methods suitable for tool condition monitoring. In his work, AE signals are monitored during rough and finish honing of cylinder liner using fresh and completely worn out honing tools. No investigations are carried out on a retrofitted horizontal honing machine, keeping in view of the suggested modifications, we hope that it will be of great interest for the small and medium industries.

\section{Retro fitting honing attachment to lathe}

A lathe of one meter admits between centers is used for retro fitting. The main head stock and tail stock are replaced by work fixture and tool motor. The base of tail stock is retained and a geared motor of 60rpm is used for primary cutting motion. A special fixture is designed to hold a cylinder liner of $200 \mathrm{~mm}$ bore. A hydraulic circuit is used to move the honing tool on the external slide ways of the bed. The power pack for copy turning is used for this purpose, fixture is mounted on internal slide ways and is fastened permanently. The entire setup is shown in Figure 1. The hydraulic circuit is show in Figure 2. No attempt is made to patent the design and the small industries which cannot afford expensive super finish operations are most welcome to use the above design. Honing as a rule is to be carried out in a medium to reduce the temperature gradient and for removal of fine chips produced in the process. The coolant pump and reservoir of the lathe are used for this purpose; the medium used in the present work is kerosene. Hence, the fixture holding the work piece is to be designed considering the flow of medium.

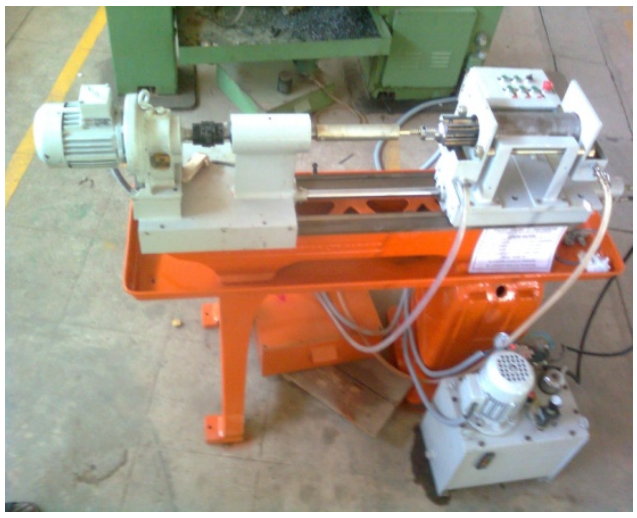

Figure 1(a) Retro fitted lathe with honing attachment

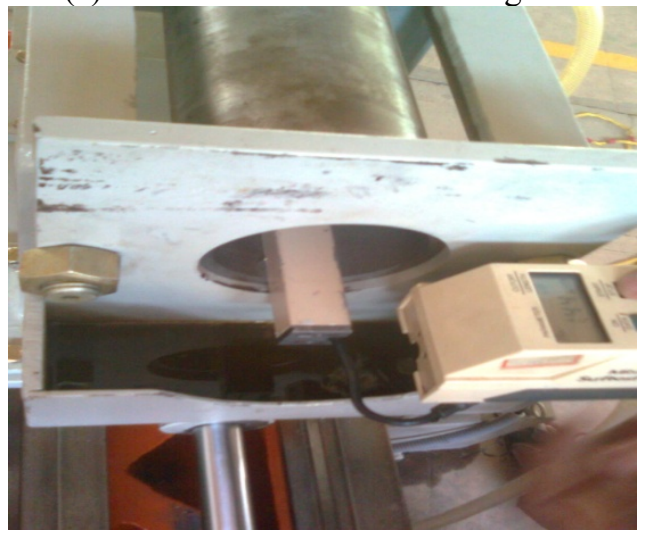

Figure 1 (c) Surface roughness measurement using Talysurf

Figure 1: Experimental set up

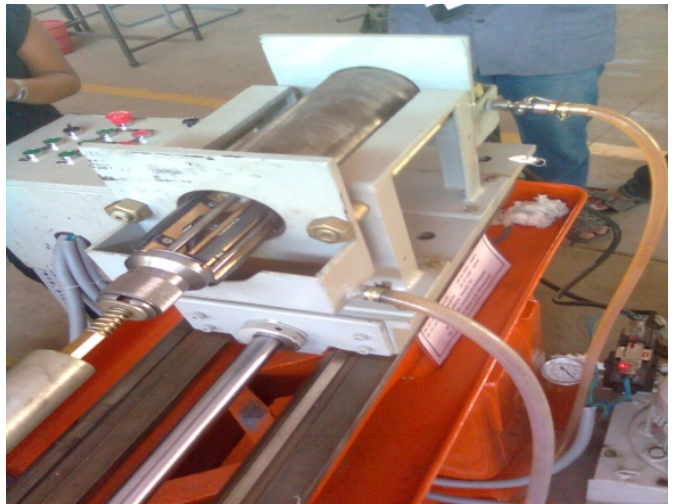

Figure 1 (b) Hydraulic sliding system

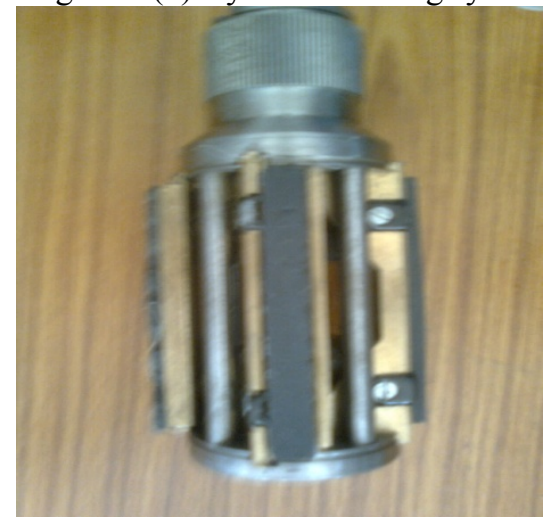

Figure 1 (d) Rotary honing tool 


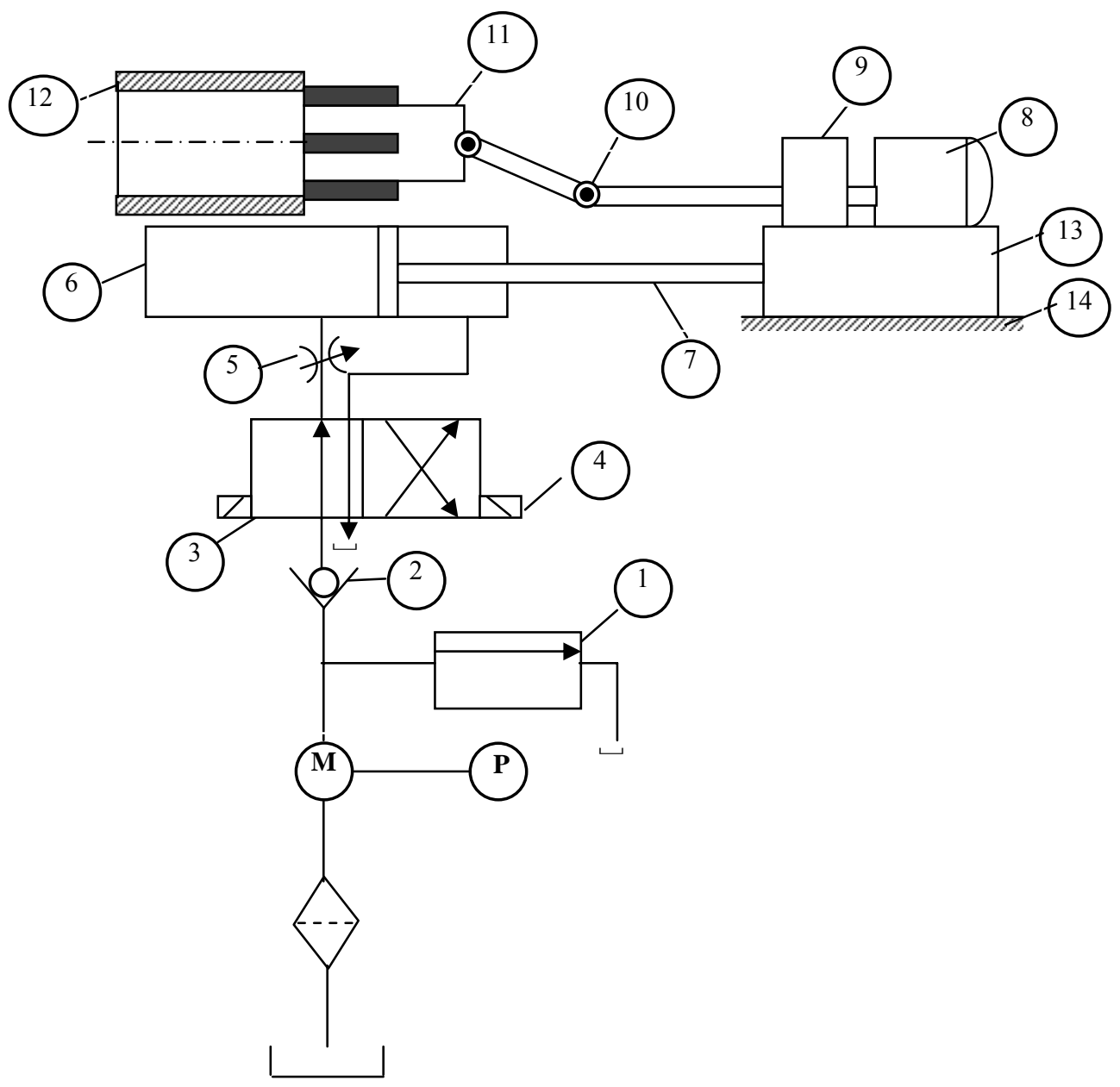

1. Relief Valve

2. Check Valve

3. DC valve

4. Solenoid

5. Flow control valve

6. Hydraulic Cylinder

7. Piston Rod
8. Motor

9. Gear Box

10. Hook Joint

11. Honing Tool

12. Liner

13. Lathe Saddle

14. Guide Way

Figure 2: Hydraulic circuit diagram of the retrofit.

The hydraulic cylinder is selected from standard data available in the literature and is given in Table 1.

Table: 1 Max pressure and feeds of cylinders

Type 1 (30mm bore cylinder) Type 2 (50 $\mathrm{mm}$ bore cylinder)

Maximum operating pressure $15.09 \mathrm{MPa}$

$6.36 \mathrm{MPa}$

Maximum feed

$67.5 \mathrm{~m} / \mathrm{min}$

$28.62 \mathrm{~m} / \mathrm{min}$

Upon comparison of the various parameters of the two different cylinders the natural choice is the cylinder with $50 \mathrm{~mm}$ bore. The reasons are enunciated below. The maximum operating pressure is low in $50 \mathrm{~mm}$ bore; hence, the risk of failure at high pressures is reduced. The cost of machining and fabrication of the $30 \mathrm{~mm}$ bore cylinder is more than the other. The machine is a modified 1.5 meter centre lathe. On one end of the lathe bed, the hydraulic cylinder along with the fixture holding the work piece is bolted. At the other end, a saddle housing the geared motor, spindle attachments and tool is located. The piston rod is connected to the saddle for sliding the tool into work over the slide ways of the bed. The reciprocation of the tool is obtained by using a hydraulic circuit shown in figure 2. A solenoid controlled 2/4 DC valve is used to get forward and reverse travel and flow control valve is used to control the linear travel of the tool. 


\section{Experimentation}

A seamless steel liner of internal diameter $80 \mathrm{~mm}$ and length $300 \mathrm{~mm}$ is taken as the work piece. A four stick honing tool with a variable diameter range of $75 \mathrm{~mm}$ to $120 \mathrm{~mm}$ was used to machine it. For better results three different grains of honing sticks of aluminum oxide were used. These are: 1. Coarse grain sticks (180) 2. Medium grain sticks (220) 3. Fine grain sticks (260). The machining process was carried out for different conditions and the surface finish is measured repeatedly to avoid errors and bias. Mean value of surface roughness is obtained. A Mitutoyo make digital Talysurf was used to measure the surface roughness. The readings are directly obtained as $R_{a}$ in $\mu \mathrm{m}$. Metal Removal Rate (MRR) for various feeds are computed using a Mitutoyo make bore gauge, and are shown in Table 2 .

M.R.R=Volume of material removed per $\min =$ Contact perimeter $\mathrm{X}$ depth of cut $\mathrm{X}$ feed per $\min \mathrm{X}$ No of revolutions

Table: 2 Metal removal Rates for Different Feeds.

\begin{tabular}{|c|c|}
\hline Feed 's' $(\mathrm{m} / \mathrm{min})$ & Metal Removal Rate "Q' in $\mathrm{mm}^{3} / \mathrm{min}$ \\
\hline 0.21 & 1.15 \\
\hline 0.64 & 3.44 \\
\hline 1.07 & 5.74 \\
\hline 1.94 & 10.51 \\
\hline
\end{tabular}

\section{Results and Discussions}

The grain sizes used are coarse (180 meshes), medium (220 mesh) and fine (260 mesh). While machining with coarse size grain sticks, more work surface and tool material was removed, and a total of two sets of sticks were consumed, during experimentation. During machining with medium size grain sticks, lesser work piece and tool material was removed and hence one set of sticks was sufficient for the machining process and the machining involving fine size grain sticks, a small amount of work piece and tool material was removed. And hence, only one set stick material was consumed. The various parameters in each condition are given in Tables 3 to 5 .

Table - 3 Coarse Grain Stick roughness values

\begin{tabular}{|l|l|l|l|l|l|l|l|l|}
\hline Condition & 1 & 2 & 3 & 4 & 5 & 6 & 7 & 8 \\
\hline Feed $(\mathrm{m} / \mathrm{min})$ & 0.21 & 0.21 & 0.64 & 0.64 & 1.07 & 1.07 & 1.94 & 1.94 \\
\hline Pressure $(\mathrm{MPa})$ & 0.2 & 0.2 & 0.5 & 0.5 & 0.8 & 0.8 & 1.8 & 1.8 \\
\hline Lubrication & Dry & Wet & Dry & Wet & Dry & Wet & Dry & Wet \\
\hline $\begin{array}{l}\text { Surface roughness mean } \\
\text { value }(\mathrm{Ra} \text { in } \mu \mathrm{m})\end{array}$ & 2.74 & 2.92 & 2.42 & 2.32 & 2.11 & 1.91 & 2.6 & 2.28 \\
\hline
\end{tabular}

Table -4 Medium Grain Stick roughness values

\begin{tabular}{|l|l|l|l|l|l|l|l|l|}
\hline Condition & 1 & 2 & 3 & 4 & 5 & 6 & 7 & 8 \\
\hline Feed $(\mathrm{m} / \mathrm{min})$ & 0.21 & 0.21 & 0.64 & 0.64 & 1.07 & 1.07 & 1.94 & 1.94 \\
\hline Pressure $(\mathrm{MPa})$ & 0.2 & 0.2 & 0.5 & 0.5 & 0.8 & 0.8 & 1.8 & 1.8 \\
\hline Lubrication & dry & wet & dry & wet & dry & wet & dry & wet \\
\hline $\begin{array}{l}\text { Surface roughness mean } \\
\text { value }(\mathrm{Ra} \text { in } \mu \mathrm{m})\end{array}$ & 1.63 & 1.26 & 1.33 & 1.04 & 0.94 & 0.86 & 1.13 & 1.01 \\
\hline
\end{tabular}

Table 5: Fine Grain Stick roughness values

\begin{tabular}{|l|l|l|l|l|l|l|l|l|}
\hline Condition & 1 & 2 & 3 & 4 & 5 & 6 & 7 & 8 \\
\hline Feed $(\mathrm{m} / \mathrm{min})$ & 0.21 & 0.21 & 0.64 & 0.64 & 1.07 & 1.07 & 1.94 & 1.94 \\
\hline Pressure(MPa) & 0.2 & 0.2 & 0.5 & 0.5 & 0.8 & 0.8 & 1.8 & 1.8 \\
\hline Lubrication roughness & dry & wet & dry & wet & dry & wet & dry & wet \\
\hline $\begin{array}{l}\text { Surface } \\
\text { mean value }(\mathrm{Ra} \text { in } \mu \mathrm{m})\end{array}$ & 0.66 & 0.57 & 0.46 & 0.43 & 0.35 & 0.33 & 0.39 & 0.36 \\
\hline
\end{tabular}

The influence of feed on surface roughness, for various grain sizes is depicted in Figures 3 to 6 . 


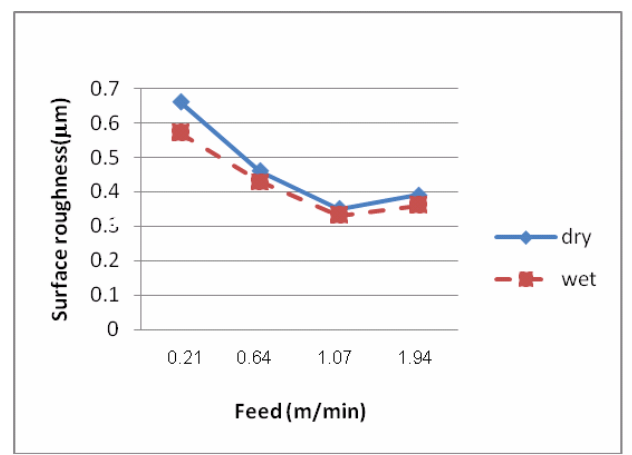

Figure 3. Fine grain sticks (Grade 260)

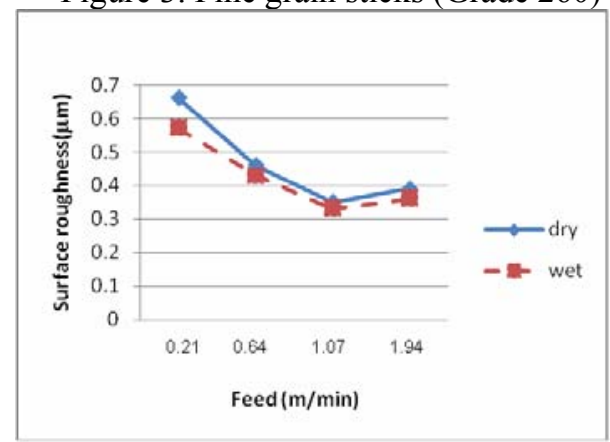

Figure 5. Fine grain sticks (Grade 180)

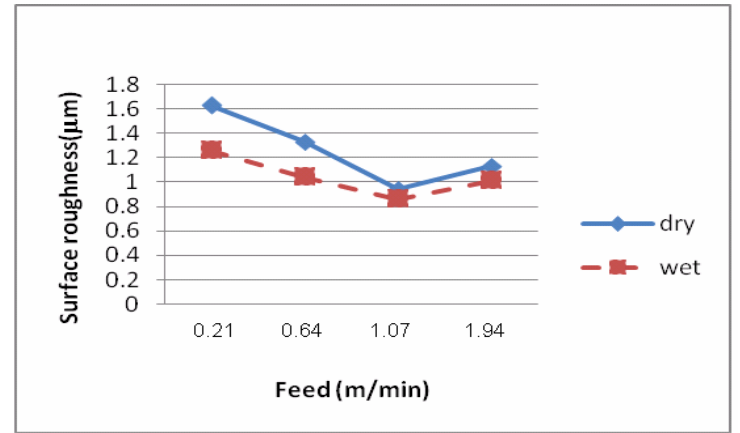

Figure 4. Medium grain sticks (Grade 220)

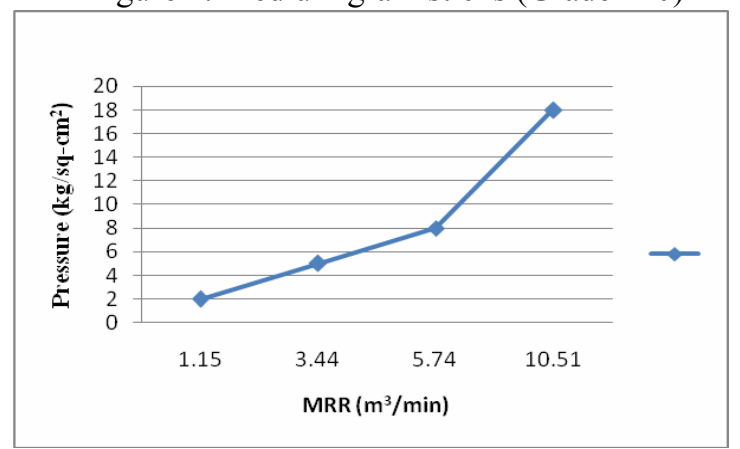

Figure 6. Variation in pressure against MMR

A general purpose lathe with hydraulic power pack can be modified as horizontal honing machine with a cost of Rs 50,000 (\$1000).The surface finish is superior and the geometry of the hole can be corrected. Hydraulic feed is smooth and aided in getting better surface finish. Single phase geared motor is used for the present application. This can be changed to pole changing motor to enhance the range of the machine. Forces and torque generated in honing is very less. Hence, no attempt is made to measure these parameters. The quality of the surface finish obtained in the medium is superior. The most important observation is that the working height of the machine is very convenient to the operator and can work without any fatigue. Hook joint permitted the tools to stay in floating condition. This principle can be extended to vibratory honing, by providing vibrations with required frequency to the tool. The influence of gravity on the over hanged work piece is ignored during the experiments. It is a point to be noted that due to cantilever action, there may be a minor geometric error in the hole generated. This effect will be considered as an extension of the present work.

\section{Conclusions}

Based on the above results and discussion, the following conclusions can be drawn:

- The best surface roughness obtainable on this machine is $0.3 \mu \mathrm{m}$.

- The optimum feed to get the best possible surface finish is identified as $1.07 \mathrm{~m} / \mathrm{min}$.

- The finish in dry honing is not satisfactory. Hence, as a rule, medium is essential for this process.

- The tool is protected from over loads by the relief valve used in hydraulic circuit.

- The hydraulic line pressure is directly proportional to the metal removal rate

- As the pressure increases, feed increases linearly.

- This method yields best possible surface finish at minimum cost.

- When coarse grain abrasive is used the MRR is equivalent to grinding

\section{Acknowledgement}

The authors are sincerely thankful to the Principal and Management of Vasavi College of Engineering for extending their support in carrying out this work. The cooperation extended by Mr. T. Manohar Reddy, Lab Technician, during experimentations is highly appreciated. 


\section{References}

Anderberg C., Cabanettes F., Dimkovski Z., Ohlsson R., Rosén B.-G., 2013, Cylinder liners and consequences of improved honing, NT2006-11-7 Downloaded September, 2013.

Dimkoski Z., Anderberg C., Rosen B.G., Ohlsson R. and Thmoas T.R., 2009. Quantification of the cold worked material inside the deep honing grooves on cylinder liner surfaces and its effects on wear, Wear, Vol. 267, No. 12, pp. 2235-2242.

Guo Y.B., Zhang Y., Zhong J.A. and Syoji K., 2002. Optimization of honing wheel structure parameters in ultra precession plane honing, Journal of Material Processing Technology, Vol. 129, No. 1-3, pp. 96-100.

Jingqiang Z., Guhie W., Wanshan W., 2010. Optimization design of segmented grinding wheel structure on super high-speed', computer-aided industrial design and conceptual design, IEEE $11^{\text {th }}$ international Conference 2010, pp. 17-19.

Kanthababu M., Shunmugam M.S., Singaperumal M.. 2008. Tool condition monitoring in honing process using acoustic emission signals, International Journal of Automation and Control, Vol. 2, No. 1, pp. 99-112.

Rodrigues M.R.P.C., Porto S.F., Torque Plate Honing on Block Cylinder Bores”. Cummins Brasil Ltd, Brasil.

Voronov S.A. 2009. Modeling of bore honing, International Journal of Mechatronics and Manufacturing System, Vol. 2, No 5/6, pp. 566-579.

\section{Biographical notes}

Dr. K. Kishore received his Ph.D. in Metal Cutting from Osmania University, Hyderabad, India, in 2006. He is working as a Professor at the Department of Mechanical Engineering, Vasavi College of Engineering, Hyderabad, India. He has 20 years of teaching and research experience. He has published 12 papers in International journals and 4 papers in National Journals and also presented 8 papers in International and National Conferences. His areas of interest are metal cutting, welding, Automobile Engineering, genetic algorithms, Nano materials. Presently he is guiding four research scholars. He is also a member of various professional societies.

Mr. P.V. Gopal Krishna received the B.E and M.E degrees from Andhra University, Visakhapatnam, India, in Mechanical Engineering and Industrial Engineering in the year 1998 and 2000 respectively. He has 13 years of experience in the field of teaching at graduate and post graduate level. He has published 10 papers in International Journals, 2 paper in National Journal and 6 papers in International and National Conferences. Presently he is Associate Professor in the Department of Mechanical Engineering, Vasavi College of Engineering, Hyderabad, India. He is life member in professional bodies like ISTE,IE(I).

Mr. G. Kiran Kumar had a teaching experience of 15 years. He worked as Assistant Professor in the Department of Mechanical Engineering at Vasavi College of Engineering, Hyderabad, India. His research interest included manufacturing and design. He graduated from Nagarjuna University in 1999 with specialization in Mechanical Engineering. He obtained post graduate degree in Machine design from Guindy College of Engineering, Anna University, Chennai.

Prof. T. Srihari received B.Tech from Sri Venkatewara Univerity, Tirupati, India, M.E from Osmania University, Hyderabad, India and Ph.D from Indian Institute of Technology Delhi, India. He is working as a Professor at the Department of Mechanical Engineering, Shadan College of Engineering and Technology, Hyderabad, India. He has 25 years of teaching and research experience. He has published 24 papers in International journals and 9 papers in National Journals and also presented 32 papers in International and National Conferences. His areas of interest are welding, metal cutting, ceramics, composite materials, design of experiments and optimization.

Received October 2011

Accepted June 2012

Final acceptance in revised form September 2013 